\title{
The Impact of Inverse Learning Style in Learning Teaching Skills for Third-Year Students' Faculty of Physical Education and Sports Sciences - Diyala University
}

\author{
Dr. Ahmed Aqeel ${ }^{1}$, Prof. Dr.Hanan Adnan Aboob ${ }^{2}$, Prof. Dr.BasmaNaeem Mohsin ${ }^{3}$ \\ University of Diyala, College of Physical education and sport science. \\ ahmed.aqeel@uodiyala.edu.iq
}

\begin{abstract}
The modern educational philosophy focuses on the student, especially in the subject of teaching methods being the center of the educational process, the teaching process must look at the student comprehensively taking into account the different patterns of their learning, the scientists of physical education from a few decades tended to focus on providing students with methods and skills of self-learning, and critical thinking, so I use The researcher's experimental method for its suitability of the nature of the research, with the tight control of the tribal and dimensional test of the experimental and control groups only and was based on the dimensional measurement only of the variable of the cognitive achievement measure for teaching skills, was determined the meeting of the research meeting students of the third stage- Faculty of Education Physical and Sports Sciences - Diyala University, numbering 190 students, was identified as an experimental and controlled research sample in a random, irregular way (lottery) and division (A) was also selected by lot, as the division (a) was selected experimental and division b officer The total number of students (32) students divided into two groups of (16) students per group and a percentage $(16,842)$ and the proposed curriculum (8) teaching units and two teaching units per week with a time of (90) minutes For the single teaching unit, the tests were conducted and data collected before the start of the curriculum and repeated it after completing all teaching skills after the curriculum and after statistical analysis system(sps)the results showed that the inverse learning method has a positive effect on teaching skills and concluded the researcher that the inverse learning style has direct effectiveness in learning teaching skills and then the method followed (command)..
\end{abstract}

Keywords

Inverse Learning Teaching Skills.

Article Received: 16th October, 2020; Article Revised: 30th December, 2020; Article Accepted: 08th January, 2021

\section{Introduction}

The modern pedagogical philosophy focuses on the student, especially in the subject of teaching methods as it is the focus of the educational process, the teaching process must look at the student in a comprehensive view taking into account the different patterns of their learning (Zidan, 2013), the scientists of physical education from a few decades have tended to focus on providing students with methods and skills of self-learning, critical thinking, communication and collaborative work in order to solve the problems facing them in their learning in a creative way (Mohamed And Mina, 2011 2. The teacher is the focus of the educational process, and the student is a passive recipient of information only 
without interacting with it, as the teacher explains the educational material during the lessons and then the students go home to deal with problems and solve duties on their own, which leads to their reluctance to solve duties and sometimes become frustrated, because of the low ability to solve problems at other times (Mitwali, 2015). The available and appropriate technology, helped to transform the traditional class or lecture style that is limited to teaching within the class, and by relying on the method of lecture and indoctrination by the teacher, from this point of view and with the scientific and technological progress achieved, emerged on the scene strategies and methods of teaching modern seeks to reshape the educational process, to change the traditional role played by school and home, where the student takes a more active role in taking responsibility for his learning, among these methods seek to follow the method of learning and the reverse learning is one of the integrated methods of learning, It is an educational system that benefits from all the technological possibilities and media available, by combining more than one method and a learning tool, whether electronic or traditional, to provide a new quality of learning that suits the characteristics and needs of learners on the one hand, and fits the nature of the course and the educational objectives that we seek on the other hand (Awad and Abu Bakr, 2010).

Active, the role of the teacher is directed and mentored to students to apply what they have learned (2014, Calvin.) Others johnson points out that inverse learning, which is a pattern of integrated learning, which combines the activation of technology in learning without losing sight of the role of teacher-learner interaction with the presence of technology and its tools as specific tools for effective learning to be a candidate for fundamental changes in the educational context and educational institutions, the learning style Inverse works to enrich the educational process, achieve positive learning outcomes at the cognitive level of increased achievement, and skills of acquiring teaching skills and motor skills, and emotional, which is the love of the subject and positive interaction with it within the classroom between teacher and students or between students with each other. Through the researcher's work in teaching methods to third-year students, he noticed what was happening in the class today, the students come, take their seats, and walk through a presentation of the content of the course.

Sometimes I have a Power Point chip, or make students make observations that may ask students to acquire knowledge by interacting with each other as well as the large numbers of students in a class, as our students do not interact with information, they only absorb information, and research and studies show us that whatever you offer students in class, 20 to $80 \%$ of it will be absorbed, all very effective teaching methods include students who interact and work within the content, not just sit, listen and absorb the content.

Inverse learning will teach our students how to acquire knowledge at home using a variety of learning techniques and tools to provide them with success, get out of class and learn the things they need to learn. We will devote $100 \%$ of the educational time, to helping them learn better. Hence the objectives of the research to identify the effectiveness of the inverse learning method in cognitive achievement and learn teaching skills for third-stage students to learn about the effectiveness of inverse learning on third-level students. As for the research assignments: There are statistically significant differences between the tribal and dimension testing and experimental and teaching skills for thirdstage students. 


\section{Literature Review}

The inverse learning style is called several terms such as inverted learning style, feedback, reverse learning style and has several definitions that the concept of inverse learning style means that: "What is done at home within traditional learning is done during class and what is done during

\section{Research Methodology}

The researcher used the experimental method to suit the nature of the research, as this method is the best that can be followed to reach accurate results, which is known as "the deliberate and controlled change of the specific conditions of a particular incident, and then note the resulting changes in this same incident as well as its interpretation (AmerIbrahim Qandilji:148:2012)

\section{1) Research community and} Research samples

The researcher identified the research community of the third stage students Faculty of Physical Education and Sports Sciences - Diyala University numbering (190) students, for the academic year the class in traditional learning is done at home. The student's presentation of the subject outside the lesson, whether through an educational video recorded by the teacher to explain a particular lesson or readings related to the subject of the lesson. ( Bergman : 14:2012).

(2018-2019) divided into five divisions (A, $\mathrm{B}, \mathrm{C}, \mathrm{D}, \mathrm{E})$ and a division of female students who were removed from the research community, The sample of experimental and controlled research was determined in a random irregular way (lottery) and division (A,D) was also selected by lot, as the division (a) experimental and division (b) officer was selected as the total number of samples (32) students divided into two groups by (16) students Per group in percentage $(16,842)$

Search tools:

Tools used:

Student registration form

Teaching skills scale

Inverse teaching curriculum:

\section{Table (1)}

Shows the arithmetic mean, the standard deviation, the calculated(T)value, and the error ratio.

\begin{tabular}{|c|c|c|c|c|c|c|c|c|}
\hline \multirow{2}{*}{ Variables } & \multirow{2}{*}{$\begin{array}{l}\text { Unit of } \\
\text { measu } \\
\text { rement }\end{array}$} & \multicolumn{2}{|c|}{$\begin{array}{l}\text { Experimental } \\
\text { Group }\end{array}$} & \multicolumn{2}{|c|}{$\begin{array}{l}\text { The command } \\
\text { group }\end{array}$} & \multirow{2}{*}{$\begin{array}{l}\text { Calculat } \\
\text { ed T }\end{array}$} & \multirow{2}{*}{$\begin{array}{l}\text { Error } \\
\text { rate }\end{array}$} & \multirow{2}{*}{$\begin{array}{l}\text { The } \\
\text { signif } \\
\text { icanc } \\
\text { e }\end{array}$} \\
\hline & & A & STD & A & STD & & & \\
\hline $\begin{array}{ll}\text { Field } & \text { of } \\
\text { planning }\end{array}$ & $\begin{array}{l}\text { Degre } \\
e\end{array}$ & 32.781 & 5.546 & 32.6563 & 5.31953 & .092 & .9279 & $\begin{array}{l}\text { It's } \\
\text { not } \\
\text { moral }\end{array}$ \\
\hline $\begin{array}{l}\text { Field of } \\
\text { implementation }\end{array}$ & $\begin{array}{l}\text { Degre } \\
\mathrm{e}\end{array}$ & 23.094 & 5.47345 & 25.468 & 2.96196 & -2.159 & .0350 & $\begin{array}{l}\text { It's } \\
\text { not } \\
\text { moral }\end{array}$ \\
\hline
\end{tabular}




\begin{tabular}{|l|l|l|l|l|l|l|l|l|}
\hline Field calendar & $\begin{array}{l}\text { Degre } \\
\mathrm{e}\end{array}$ & 17.256 & 4.1434 & 17.156 & 4.142 & 1.000 & 0.000 & $\begin{array}{l}\text { It's } \\
\text { not } \\
\text { moral } \\
\text { the scale }\end{array}$ \\
& $\begin{array}{l}\text { Degre } \\
\mathrm{e}\end{array}$ & 73.031 & 7.5412 & 75.281 & 7.463 & -1.200 & .2350 & $\begin{array}{l}\text { It's } \\
\text { not } \\
\text { moral } \\
.\end{array}$ \\
\hline
\end{tabular}

The module was taught with 8 class classes in addition to eight educational videos that fit the content and objectives of the teaching unit included in the curriculum of teaching methods for students of the third stage - Faculty of Physical Education and Sports Sciences University Diyala, as the students were watching the video dedicated to the lesson before explaining it at home to those who have internet access and the college for Those who do not have internet access, by watching the videos, have the opportunity to take notes and questions about what they have seen, to be the starting point of the discussion in the classroom the next day, in addition to the worksheets and activities that are accomplished through groups through which students communicate with each other and the subject and the teacher as well

Research Results

View the results, analyze and discuss the results of the research variables:

View, analyze and discuss the results of search variables:
Tests used:

Teaching Skills Scale (Sinan Abbas:2012) Parity and homogeneity: If the sample is classified for a particular category or class, it is considered to be homogeneous among themselves, considering that each of them is equal and qualified for the category and is at their level. (Zafer Kadhim:2013:45)

The procedure of parity between groups:

For the purpose of starting from one starting point and attributing the results that appear after applying the independent variable only and not to something else, the researcher only tested between the three areas of the scale of the equivalence of the experimental and control groups.

Two groups of students were taught, one studied in the usual way and the other studied using the inverse learning method, and the researcher used a measure of teaching skills and reached

\section{Table (2)}

The arithmetic medium and deviation shows the standard, the differences of the mathematical circles, the percentage of the errors and the value of the $(t)$ calculated for the experimental group

\begin{tabular}{|l|l|l|l|l|l|l|l|l|l|l|l|}
\hline Variables & $\begin{array}{l}\text { The } \\
\text { Unit of } \\
\text { The } \\
\text { Cruel }\end{array}$ & A & STD & A & STD & $\begin{array}{l}\text { Pifferen } \\
\text { A } \\
\text { A }\end{array}$ & $\begin{array}{l}\text { Differen } \\
\text { ce } \\
\text { STD }\end{array}$ & T & $\begin{array}{l}\text { Error } \\
\text { rate }\end{array}$ \\
$\begin{array}{l}\text { Planning } \\
\text { area }\end{array}$ & Degree & 32.781 & 5.546 & 39.375 & 4.591 & -6.594 & 8.112 & -4.598 & .0000 & sign \\
cance
\end{tabular}




\begin{tabular}{|l|l|l|l|l|l|l|l|l|l|l|}
\hline $\begin{array}{l}\text { Calendar } \\
\text { domain }\end{array}$ & Degree & 17.156 & 4.143 & 26.063 & 3.321 & -8.9063 & 5.063 & -9.950 & .0000 & sign \\
\hline Scale & Degree & 73.031 & 7.541 & 98.219 & 7.033 & -25.187 & 7.843 & 18.167 & .0000 & sign \\
\hline
\end{tabular}

Table (2) Shows the value of the arithmetic medium, the standard deviation, the differences of the calculation circles, the percentage of the error rate and the value $(\mathrm{t})$ calculated for the experimental group, with the value of the arithmetic medium in the Pre-test of the planning field (32.781) and the standard deviation (5.546)and the arithmetic average in the distance test of the planning field(39.375)and standard deviation (4.591) The ratio of the circles difference (-6.594), the deviation difference (8.112) and the value(T)(calculated) was 4.598), the value of the arithmetic medium in the Pre-test of the implementation field (23.094) and the standard deviation (5.473)and the arithmetic average in the remote test of the implementation field
(32.781) and the standard deviation of the implementation field(32.781)and the standard deviation (5.473) The ratio of the circles difference (-9.6875) and the difference of deviations (8.660) and the value(T(calculated) -6.328 , with the value of the arithmetic medium in the Pre-test of the calendar field (17.156) and a standard deviation (4.143)and the arithmetic medium in the distance test of the calendar field(26)With a standard deviation (3.321) the ratio of the circles difference $(-8.9063)$ and the difference of deviations (5.063) and the value(T)9.950) and the ratio of sin for the three areas (.0000), which means a moral difference between the Pre and dimension tests and in favour of the three magazines in the Post-test.

\section{Table(3)}

The arithmetic medium and deviation shows the standard, the differences of the mathematical circles, the difference of the standard deviations, the percentage of the errors and the value of the (t) calculated for the control group.

\begin{tabular}{|c|c|c|c|c|c|c|c|c|c|c|}
\hline \multirow{2}{*}{ Variables } & \multirow{2}{*}{$\begin{array}{l}\text { The } \\
\text { Unit } \\
\text { of The } \\
\text { Cruel }\end{array}$} & \multicolumn{2}{|c|}{ Pre-Test } & \multicolumn{2}{|c|}{ Post-Test } & \multirow{2}{*}{$\begin{array}{l}\text { Differen } \\
\text { ces } \\
\text { A }\end{array}$} & \multirow{2}{*}{$\begin{array}{l}\text { Differ } \\
\text { ences } \\
\text { STD }\end{array}$} & \multirow{2}{*}{$\mathbf{T}$} & \multirow{2}{*}{$\begin{array}{l}\text { Error } \\
\text { rate }\end{array}$} & \multirow{2}{*}{$\begin{array}{l}\text { The } \\
\text { signifi } \\
\text { cance }\end{array}$} \\
\hline & & $\mathbf{A}$ & STD & $\mathbf{A}$ & STD & & & & & \\
\hline $\begin{array}{l}\text { Planning } \\
\text { area }\end{array}$ & $\begin{array}{l}\text { Degre } \\
\text { e }\end{array}$ & 32.656 & 5.320 & 25.469 & 2.962 & 7.188 & 5.306 & 7.662 & .0000 & sign \\
\hline $\begin{array}{l}\text { Field of } \\
\text { implemen } \\
\text { tation }\end{array}$ & $\begin{array}{l}\text { Degre } \\
\text { e }\end{array}$ & 25.469 & 2.962 & 17.281 & 4.105 & 8.188 & 5.438 & 8.516 & .0000 & sign \\
\hline $\begin{array}{l}\text { Calendar } \\
\text { domain }\end{array}$ & $\begin{array}{l}\text { Degre } \\
\text { e }\end{array}$ & 17.156 & 4.144 & 17.312 & 3.126 & -0.1563 & 5.737 & 0.154 & .8790 & sign \\
\hline Scale & $\begin{array}{l}\text { Degre } \\
\text { e }\end{array}$ & 75.281 & 7.463 & 60.063 & 6.451 & 15.219 & 9.530 & 9.034 & .0000 & sign \\
\hline
\end{tabular}

Table (3) Shows the value of the arithmetic medium, the standard deviation, the differences of the calculation circles, the percentage of the error rate and the value of the control group, which was the value of the arithmetic medium in the Pre-test of the planning field (32.656) and the standard deviation (5.320)and the computational medium in the distance test of the planning field(25.469)and the 
standard deviation (2.9) 62) The ratio of the circles difference (7.188) and the differencedifference (5.306) and the value(T)calculated (7.662), the value of the arithmetic medium in the Pre-test of the field of implementation (25.469) and the standard deviation (2.962)and the arithmetic average in the remote test of the field of implementation(17.281)With a standard deviation (4.105) and the ratio of the circles difference (8.188) and the difference of deviations (5.438) and the value $(\mathrm{T})$ (calculated) 8.516 , the value of the arithmetic medium in the Pre-test of the calendar field (17.156) and the standard deviation (4.143)and the arithmetic medium in the distance test of the calendar field 17.156)and with a standard deviation (3.126) and the ratio of the difference of circles $(-0.1563)$ and the difference of deviations (5.737) and the value( $\mathrm{T})$ (calculated) (0.154) and the ratio of $\sin$ for the three areas (.0000) which means a moral difference between the Pre and dimension tests and in favour of the three magazines in the Post-test.

\section{Table(4)}

Shows the computational medium, the standard deviation, the calculated(T)value, and the error rate of the experimental group and the control of the after-Postest.

\begin{tabular}{|c|c|c|c|c|c|c|c|c|}
\hline \multirow{2}{*}{ Variables } & \multirow{2}{*}{$\begin{array}{l}\text { Unit } \\
\text { of } \\
\text { meas } \\
\text { urem } \\
\text { ent }\end{array}$} & \multicolumn{2}{|c|}{$\begin{array}{l}\text { Experimental } \\
\text { Group }\end{array}$} & \multicolumn{2}{|c|}{$\begin{array}{l}\text { The command } \\
\text { group }\end{array}$} & \multirow{2}{*}{$\begin{array}{l}\text { Calculat } \\
\text { ed T }\end{array}$} & \multirow{2}{*}{$\begin{array}{l}\text { Error } \\
\text { rate }\end{array}$} & \multirow{2}{*}{$\begin{array}{l}\text { The } \\
\text { signifi } \\
\text { cance }\end{array}$} \\
\hline & & $\mathbf{A}$ & STD & $\mathbf{A}$ & STD & & & \\
\hline $\begin{array}{l}\text { Planning } \\
\text { area }\end{array}$ & $\begin{array}{l}\text { Degre } \\
\text { e }\end{array}$ & 39.375 & 4.591 & 25.469 & 2.962 & 14.397 & 0.000 & $\begin{array}{l}\text { Spirit } \\
\text { ual }\end{array}$ \\
\hline $\begin{array}{l}\text { Field of } \\
\text { implement } \\
\text { ation }\end{array}$ & $\begin{array}{l}\text { Degre } \\
\text { e }\end{array}$ & 32.781 & 5.546 & 17.2813 & 4.105 & 12.707 & 0.000 & $\begin{array}{l}\text { Spirit } \\
\text { ual }\end{array}$ \\
\hline $\begin{array}{l}\text { Calendar } \\
\text { domain }\end{array}$ & $\begin{array}{l}\text { Degre } \\
\text { e }\end{array}$ & 26.063 & 3.321 & 17.3125 & 3.126 & 10.853 & 0.000 & $\begin{array}{l}\text { Spirit } \\
\text { ual }\end{array}$ \\
\hline Scale & $\begin{array}{l}\text { Degre } \\
\text { e }\end{array}$ & 98.219 & 7.033 & 60.063 & 6.451 & 22.617 & 0.000 & $\begin{array}{l}\text { Spirit } \\
\text { ual }\end{array}$ \\
\hline
\end{tabular}

The table (4) shows the arithmetic medium, the standard deviation, the calculated value(T)and theerror rate of the experimental group and the control of the after-PostPosttest, as the computational average of the experimental group of the planning field(39). 375) With a standard deviation (4.591) the arithmetic average of the control group (2.962) and with a deviation of 2.962 andT(calculated) was 14.397, and the median was 14.397. The arithmetic of the experimental group of the field of implementation (32.781) and with Discussions

In light of the results presented, the researcher believes that the reason why the students of the experimental group who a standard deviation (5.546) the arithmetic average of the control group (17.2813) and with a deviation of my (4.105) and reached(T)(calculated) 12.707 , with the arithmetic average of 26.063 and a standard deviation of 3.321 and the computational average of the control group (17.3125) With a deviation of 3,126 and10,853 (calculated) $t$, the sin ratio for the three areas was 1.0000 , which meant a moral difference and in favour of the three journals in the dimension test.

studied the inverse learning method excelled based on the students of the control group who studied in the 
traditional way in the subject of teaching methods in increasing awareness and awareness of the subject by students as this method provided a broad base of information about the subject helped students to understand the problems they face during the lesson, increasing the fluency and diversity of their ideas when giving them educational or interactive video that includes the scientific subject by voice and images Not more than ten minutes. Students are directed to watch video from the Internet or CDs at home and then apply the concepts that students learn from the video in the lesson and then evaluate the student's in-class learning with appropriate calendar tools. This method has put the student in an active and effective position. The researcher also attributes the reason for this result to the fact that the questions raised are vital and active during the lesson and lead students to think and have discussions between the students themselves on the one hand and between the teacher and students on the other, all of this led to an increase in their cognitive level, in addition to the use of (inverse learning method) helped the students to acquire information and understand and remember and its ability to summon what he learned quickly and easy, if many studies emphasized the importance of the cognitive aspect to achieve Conclusion

In the results of the head and discussion, the researcher concluded: The method of inverse learning has a positive effect in improving teaching skills for students and that this method is preferred to be used within the teaching curriculum used for its effective role in improving the

[1] Abu Jado, Saleh Mohammed Ali, and Mohammed BakrNofal. Teaching theoretical thinking andpractice.(AlSamara Publishing and Distribution House, Amman, 2007).

[2] Caliph, Hassan Jaafar and Mutawa, Ziauddin Mohammed strategies for excellence In all games, which highlights the need for a more in-depth analysis to determine what the student needs from the level of knowledge that helps him to the motor duty at the required level and therefore the correlation between the application of style is important to the events of this excellence, the inverse learning method draws the attention of students to the lesson through questions that target the mental processes of inference, analysis and summary and ultimately lead to the management of deep meanings and understanding, as the method of inverse learning gives students the ability to think about examples and how they are born and this is what they have born New ideas leading to a greater understanding of the subject matter, which increased their level of education. (Abu Jado, Mohammed, 2007: 349) And this method, which is in harmony with the students on the one hand and with the nature of the subject on the other hand, has positively reflected on their cognitive achievement in the subject of teaching methods. (Afana and Youssef, 2009, 169) also contributed to stimulating the cognitive structure, in students, which increases their ability to address the new experiences and attitudes they face, and thus increase in achievement. (Lavi, 2006, 47)

performance of students during the performance of the role of teacher in the subject of teaching methods as follow all the teacher's instructions on teaching skills that achieve the desired goal

\section{References}

effective teaching. (Riyadh: Al-Mutanabbi Library272-275am) 2015

[3] Zidan, AlaaKhaldoun, Trends of Students of the Faculty of Physical Education towards teaching using computers as an aid teaching method according to the variablesof sex and the 
level ofstudy, (Al-Qadissiya Journal of Sports Education Sciences, 155-147) 2013

[4] Sinan Abbas, PhD thesis on the impact of early micro-teaching in the development of teaching skills for students at the Faculty of Physical Education (174-179a) 2012

[5] ZaferHashimKazim,scientific applications for writing letters and educational and psychological frameworks;(Baghdad University Faculty of Physical Education and Sports Sciences 2013) p. 46

[6] Amer Ibrahim Qandilji, Methodology of Scientific Research, I1: (Amman, AlYazouri Scientific Publishing House, 2012) p. 148.

[7] Afana, Azzo Ismail, and NaelaNajib alKhaznadar. Classroom teaching with multiple intelligences(Dar al-Marcha, Amman, 2007).

[8] Lavi, Said Abdullah. Reading and developing thinking,(World of Books, Cairo, 2006).
[9] For My living, IbtisamSaud,the effectiveness of inverted classes inlearning. (Medina: Dar al-Zaman Library) 2015.

[10] Mohammed, Mina, a non-linear program in mathematics to develop the ability to solve problems and tendencies towards material (Journalof Reading and Knowledge 32-36 a.m.)2012

[11] Sinan Abbas Ali (Theimpact of early micro-teaching in the development of teaching skills for students applied in the Faculty of Physical Education and Sports Sciences University Diyala, Doctoral Thesis)

[12] Calvin H. (2014). Flip Your Classroom, Scholastic instructs, Available at:

[13]

http://www.scholastic.com/teachers/article /flip-your-classroom. 